\title{
SENSORIAMENTO REMOTO APLICADO AO ESTUDO DA TEMPERATURA DE SUPERFÍCIE DA ZONA URBANA DO MUNICÍPIO DO CRATO/CE
}

\author{
Fernanda Kelly Sales Alencar $^{(a)}$, Juliana Maria Oliveira Silva ${ }^{\text {(b) }}$ \\ ${ }^{(1)}$ Estudante de Licenciatura em Geografia, Bolsista de Iniciação Científica - PIBIC/URCA, \\ Fernandakellysa95@gmail.com \\ (2) Orientadora - Doutora em Geografia, URCA, juliana.oliveitra@ urca.br
}

Eixo: 3. Climatologia em diferentes níveis escalares: mudanças e variabilidades

\begin{abstract}
Resumo
O presente trabalho tem por objetivo analisar as diferenças térmicas da superfície da zona urbana do município de Crato (Ceará) no biênio de 2016 e 2017, a partir da imagem do satélite Landsat 8TM estimando a temperatura de superfície como vegetação, solo exposto, asfalto, e sua interferência na temperatura e na sensação térmica local. A metodologia constituiu em um levantamento de material bibliográfico e cartográfico para os estudos do clima urbano além da confecção do mapa de temperatura onde a partir desse foi possível obter os seguintes resultados: As áreas de temperatura mais elevadas estão presentes em locais que apresentam maior concentração de solo exposto, pouca cobertura vegetal e concentração maior de residências. Já os locais que apresentaram temperatura mais amenas se encontrão próximos ao topo da chapada, áreas verdes e corpos d'água.
\end{abstract}

Palavras chave: Clima Urbano, Temperatura, Sensoriamento Remoto, Crato/CE

\section{Introdução}

O município de Crato está localizado no sul do Estado do Ceara, na região Nordeste do País e integra a Região Metropolitana do Cariri (RMCariri). O município possui os seguintes distritos: Crato (sede), Baixio das Palmeiras, Belmonte, Campo Alegre, Dom Quintino, Monte Alverne, Bela Vista, Ponta da Serra, Santa Fé e Santa Rosa (IPECE, 2012 (Figura 1)). Segundo os dados do censo demográfico do IBGE o Crato possui uma população de 121.428 pessoas. 


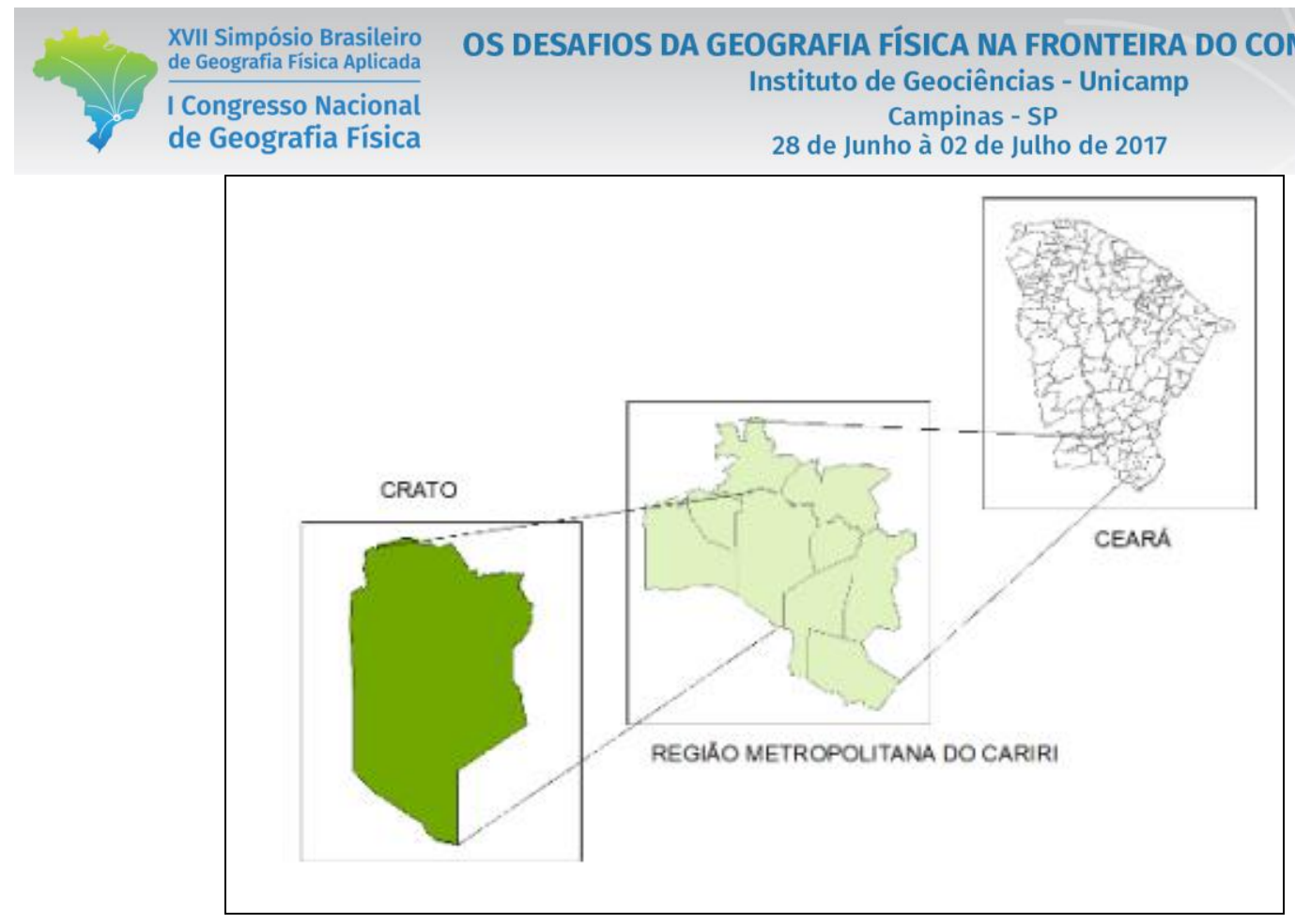

Figura 1. Localização do município do Crato/Ceará

O interesse de se trabalhar com esse tema partiu das observações das imagens de satélites da banda termal, na qual se verificou que as diferentes superfícies do solo poderiam interferir diretamente na temperatura de superfície. A pesquisa tem como objetivo analisar as diferenças térmicas da superfície zonal urbana do município do Crato para o ano de 2016, através de imagens do satélite LANDSAT 8TM, BANDA 10 (termal) e correlacionar com os diferentes tipos de uso e ocupação da cidade. Segundo Silva (2015), "a temperatura de superfície é medida a partir da energia emitida pelos objetos terrestre e captada pelos sensores". Gartland (2010) "reforça que as temperaturas de superfície são bem mais variantes do que as temperaturas de ar ao longo do dia, pois as superfícies urbanas como calçadas e coberturas, são aquecidas rotineiramente pelo sol".

\section{Metodologia}

Para o desenvolvimento dessa pesquisa e obtenção dos resultados foram realizados procedimentos divididos em etapas, que teve desde o levantamento bibliográfico apoiado em leituras sobre "Clima Urbano" com base em autores como Monteiro (1976, 2011), Gartland (2010) entre outros que trabalham essa temática, como também autores que pesquisam sobre o uso do sensoriamento remoto. A imagem do satélite Landsat 8TM banda10 do dia 14 de novembro de 2016 foi selecionada para o estudo e adquirida no site do Serviço Geológico Americano. Após a reprojeção da imagem para o Datum Sirgas 2000 Zona 24 S no software Qgis 2.18, a imagem foi exportada para o Arcgsi 10. Utilizou-se a Calculadora Raster do Arcgis para a conversão da imagem em níveis de cinza e depois para temperatura de superfície em 
graus celsius, utilizando-se as fórmulas de calibração disponibilizadas no mesmo site de aquisição da imagem. No dia da passagem do satélite efetuou-se os levantamentos de campo para o registro dos locais que poderiam gerar temperaturas diferenciadas devido ao uso e ocupação da cidade. No bairro do Centro utilizou-se um termômetro infravermelho para a coleta da temperatura de superfície com a presença de vegetação, asfalto e solo exposto para fins de comparação.

\section{Resultados e Discussões}

A partir da pesquisa realizada foi possível obter os seguintes resultados: As áreas de temperatura mais elevadas encontram-se nos seguintes bairros: Centro, Barro Branco, Muriti, Mirandão, São Bento, Parque Recreio, esses locais apresentaram uma taxa mais elevada por conter solo exposto, pouca cobertura vegetal e concentração maior de residências. Os tons de azuis mais escuros (como o topo da chapada, áreas verdes e corpos d'água) apresentam temperatura mais amenas do que os locais com temperaturas mais elevadas representadas pelos tons mais avermelhados e representam áreas com menor grau de cobertura vegetal.

Os bairros Lameiro e Granjeiro apresentam pontos avermelhados com temperaturas entre 35,2 e 40,54 representam solo exposto o que ocasionou valores elevados como está representado no mapa da distribuição de estimativa de temperatura da área de estudo na figura 1. O bairro Pimenta apresentou temperaturas variando entre 30,4 e 32,82 $2^{\circ}$; França Alencar de 26,97 e 30,44 ${ }^{\circ} \mathrm{C}$; Lameiro 26,97 e $30,44^{\circ} \mathrm{C}$, os pontos avermelhados nessa área se deve ao fato haver um loteamento e presença de solo exposto; Granjeiro variou entre 26,97 e $30,44^{\circ} \mathrm{C}$, nessa área há um manejo de solos para fins agrícolas, explicando assim o motivo da presença de pontos vermelho como mostra o mapa; já o Centro variou entre 30,44 e $32,82^{\circ} \mathrm{C}$; o Seminário entre 32,82 e $35,24^{\circ} \mathrm{C}$; Parque Recreio entre 35,24 e 40,54 ${ }^{\circ} \mathrm{C}$; São Bento 35,25 e $40,54^{\circ} \mathrm{C}$; o São Miguel variou entre 32,82 e $35,24^{\circ} \mathrm{C}$; o Muriti entre 32,82 e $35,24^{\circ} \mathrm{C}$; Mirandão entre 35,24 e $40,54^{\circ} \mathrm{C}$, o Barro Brando teve uma variação de 35,24 e $40,54^{\circ} \mathrm{C}$. 


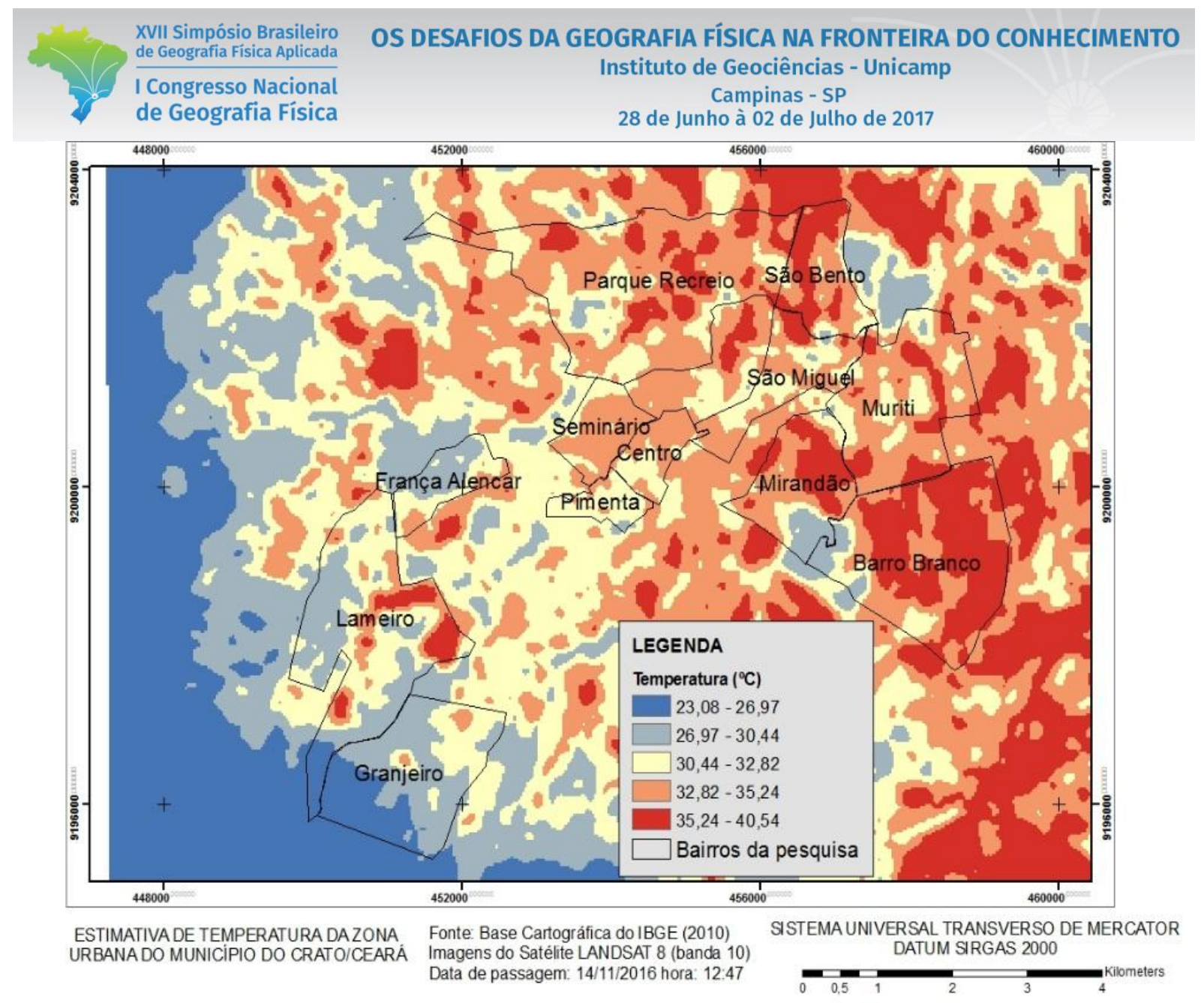

Figura 1 - Mapa da distribuição da estimativa de temperatura da área de estudo Fonte: Elaborado por: SILVA J.M.O

Dentre esses bairros, o Centro foi escolhido para levantamento de campo e para a aplicação em pontos estratégicos do termômetro infravermelho durante a passagem do satélite Landsat 8 que sobrevoou a área do estudo no dia 14 de novembro de 2016. A partir de então obteve-se os seguintes dados de temperatura de superfície com o termômetro, de acordo com a tabela 01 :

Tabela I - Coleta de Dados com o Termômetro infravermelho

\begin{tabular}{|l|c|c|}
\hline \multicolumn{3}{|c|}{ Coleta de dados do dia 14/11/2016 } \\
\hline \multicolumn{1}{|c|}{ Pontos no Centro da } & $\begin{array}{c}\text { Temperatura com a } \\
\text { presença de vegetação }\end{array}$ & $\begin{array}{c}\text { Temperatura com a presença } \\
\text { de asfalto }\end{array}$ \\
\hline Rua Dr. João Pessoa & $33,4^{\circ}$ & $46,7^{\circ}$ \\
\hline Rua Tristão Gonçalves & $32,4^{\circ}$ & $53,5^{\circ}$ \\
\hline Praça Siqueira Campos & $33,4^{\circ}$ & $51^{\circ}$ \\
\hline Praça da Sé & $33,4^{\circ}$ & $54,1^{\circ}$ \\
\hline Praça Alexandre Arraes & $34,4^{\circ}$ & $52,2^{\circ}$ \\
\hline Praça Juarez Távora & $33,4^{\circ}$ & $57,6^{\circ}$ \\
\hline
\end{tabular}


Pode-se observar na tabela os pontos de áreas com alta temperatura, no caso da Rua Dr. João pessoa e Rua Cristão Gonçalves como mostra na figura 2, não obtivemos dados de solo exposto, já em relação as praças, como exemplo a Praça da Sé como mostra a figura 3, é um local com presença de vegetação em seus arredores contribuindo assim para um ambiente com temperatura estável. A distribuição dos bairros com temperaturas mais amenas ficou da seguinte forma: Granjeiro, Lameiro e França Alencar. Essas aréas estão concentradas em relevo mais alto e com maior presença de cobertura vegetal.

Na imagem de satélite Sentinel 2A com resolução de 10 metros como mostra a figura 4, observa-se uma maior concentração de edificações nos bairros que apresentaram maiores valores de temperatura de superfície. No Parque Recreio apesar da presença de áreas verdes relacionadas aos corpos hídricos do rio da Batateiras, em muitos locais tem-se solo exposto o que ocasiona valores altos de temperatura, mesmas condições apresentadas em outros bairros, como o Barro Branco e Mirandão, este último apresenta algumas áreas que são loteadas, por isso, devido ao solo desnudo, os valores de temperatura apresentaramse maiores.

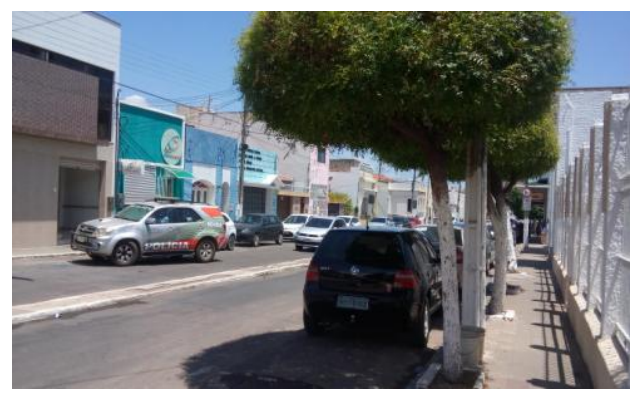

Figura 2 - Rua Cristão Gonçalves

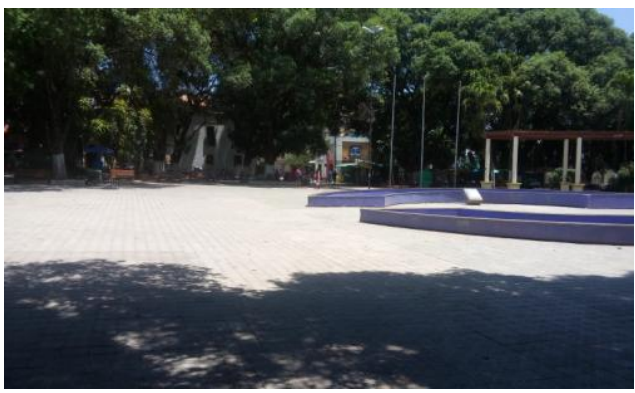

Figura 3 - Praça da Sé

Fonte: Alencar, Novembro de 2016

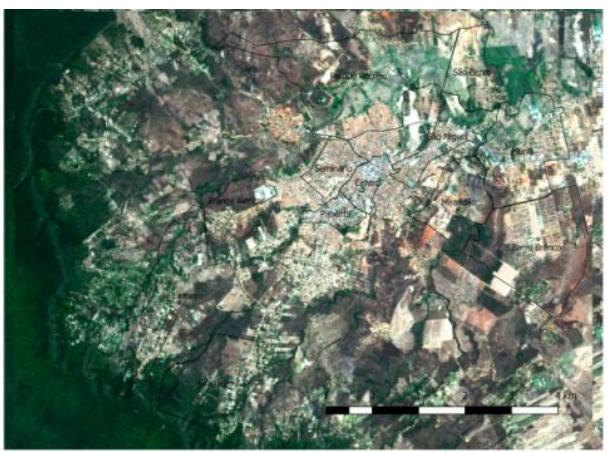

Figura 4 - Localização doMunicipio de Crato/CE. Fonte: Google Earth, 2016 


\section{Conclusão}

Foi possível perceber que fatores como solo exposto destinada a loteamentos ou agricultura, vegetação, altitude e grau de urbanização interferem nos valores de temperatura, uns proporcionando um conforto térmico e outros superaquecendo o ambiente.

\section{Bibliografia}

GARTLAND, Lisa. Ilhas de calor: como mitigar zonas de calor em áreas urbanas. São Paulo: Oficina de textos, 2010

IPECE. Instituto de Pesquisa e Estratégia Econômica do Ceará. Perfil Básico Municipal-Crato. IPECE, Fortaleza: 2012. Disponível em: <www.ipece.ce.gov.br> . Acesso em: 05 novembro de 2014

SILVA, J.M.O. Uso de serosioamento remoto para a estimativa da temperatura de superficie na microbacia do rio Granjeiro - Crato/ Ceará. Geosaberes: Revista de Estudos Geoeducacionais v.06, P.130 - 144, 2015. 